\title{
A primeira Lei de Newton: uma abordagem didática
}

\author{
Newton's first Law: a didactic approach
}

\author{
Saulo Luis Lima da Silva*10
}

${ }^{1}$ Força Aérea Brasileira, Centro de Instrução e Adaptação da Aeronáutica, Belo Horizonte, MG, Brasil

Recebido em 18 de Janeiro, 2018. Revisado em 20 de Fevereiro, 2018. Aceito em 25 de Fevereiro, 2018.

\begin{abstract}
No estudo da mecânica Newtoniana o essencial é a compreensão das leis de Newton em profundidade. Se isso acontecer, ficará fácil perceber que todos os outros fenômenos a serem estudados são consequências dessas três leis básicas do movimento formuladas por Isaac Newton. Dentre elas, a primeira lei de Newton, conhecida como lei da Inércia, é a de maior complexidade filosófica e a menos compreendida pelos alunos ao saírem de um curso de física básica. Não é incomum encontrar alunos descrevendo a primeira lei da Newton como um caso particular da segunda lei de Newton, ou princípio fundamental da dinâmica. Esse trabalho tem por objetivo discutir e esclarecer as principais dúvidas e equívocos que surgem ao se estudar a lei da inércia, bem como apresentar uma proposta de apresentação em sala de aula que possibilite uma compreensão mais aprofundada dessa lei.
\end{abstract}

Palavras-chave: primeira lei de Newton - lei da inércia - física básica - mecânica newtoniana

In the study of Newtonian mechanics, understanding of Newton's laws in depth is essential. If this happens, it will be easy to see that all other phenomena to be studied are consistent with three laws of motion formulated by Isaac Newton. In particular, Newton's first law is that of greater philosophical complexity and less comprehended by students upon leaving a basic physics course. It is not uncommon to find students describing Newton's first law as a particular case of Newton's second law. This paper aims to discuss and clarify the main doubts and misconceptions that arise when studying the law of inertia, as well as to present a proposal of presentation in the classroom that allows for a deeper understanding of this law.

Keywords: Newton's first Law - law of inertia - basic physics - newtonian machinics

\section{Introdução}

Sir Isaac Newton no prefácio à primeira edição de seu livro seminal Philosophiae Naturalis Principia Mathematica (Princípios Matemáticos de Filosofia Natural) em 1686 escreveu "Pois toda a essência da filosofia parece constituir nisso - a partir dos fenômenos de movimento, investigar as forças da natureza e, então, dessas forças demonstrar os outros fenômenos" 1]. Seguindo essa ideia, propõe que todas as forças da natureza tenham em comum o fato de seguirem o mesmo conjunto de regras. Essas regras ficaram conhecidas como as três leis de Newton para o movimento. A primeira, segunda e terceira leis de Newton são conhecidas também como lei da Inércia, princípio fundamental da dinâmica e ação e reação, respectivamente.

Antes de se iniciar um curso de mecânica newtoniana é imprescindível que se apresente qual o objetivo último da mecânica, que é o mesmo objetivo da física e até, porque não dizer, da ciência. Esse objetivo é muito simples: conhecer tudo sobre o sistema de interesse. É imediato perceber que esse é um objetivo amplo demais. Optamos, historicamente, por atacar esse objetivo por partes. A mecânica se preocupará com a posição do sistema. Como,

*Endereço de correspondência: saulolimasilva@yahoo.com.br. em geral, essa posição não é fixa, ela terá que se preocupar com as mudanças da posição no tempo, que nos levará aos conceitos de velocidade e aceleração. Vemos, portanto, que a simples tentativa de se obter a posição de um sistema nos leva, inevitavelmente, ao estudo do movimento.

O estudo do movimento compõe um dos capítulos mais interessantes e incríveis da história da ciência. Já no berço da filosofia ocidental, a grécia antiga, nos deparamos com dois pensamentos antagônicos acerca do movimento. De um lado os partidários de Parmênides defendendo o movimento como ilusório, de outro os partidários de Heráclito vendo o movimento como a essência de tudo [2 4]. Um grande expoente no estudo do movimento é também um dos pensadores mais influentes da filosofia ocidental: Aristóteles. Suas ideias, juntamente com as de Platão, permaneceram como norte da filosofia ocidental por mais de 2000 anos.

Não é possível entender todo o alcance e profundidade das leis de Newton sem um conhecimento de como o movimento era visto antes dos estudos de Newton. Particularmente, sem compreender bem as ideias aristotélicas do movimento, já que o estudo da mecânica foi dominado pelo pensamento aristotélico até ser substituído pela mecânica newtoniana. Hoje, quando apresentamos as ideias aristotélicas em sala de aula, os alunos tendem a achá-las 
ingênuas e visivelmente erradas. Um exercício muito interessante do ponto de vista didático é convidá-los a refutar essas ideias de forma clara e científica. Só dessa forma eles serão capazes de perceber que tais ideias, longe de serem óbvias, são muito razoáveis e fruto de uma mente muito poderosa. Entenderão, dessa forma, porque esse pensamento prevaleceu por mais de 2000 anos.

O trabalho está estruturado da seguinte forma: na seção II será feito um resumo das principais ideias aristotélicas sobre o movimento. A seção III é dedicada a apresentar a primeira lei de Newton e algumas consequências diretas, bem como uma discussão mais aprofundada da primeira lei de Newton que pode ser utilizada para possibilitar uma melhor compreensão por parte dos alunos da referida lei. A seção IV é dedicada às conclusões.

\section{Mecânica Aristotélica}

O importante a ser salientado aqui é que Aristóteles divide o movimento em duas partes: natural e violento. O violento é causado por forças externas, o natural é causado por forças internas. Este, por sua vez, é dividido em mais duas partes: movimento na terra e movimento celeste. Na terra, o movimento é radial, podendo ser ascendente ou descendente. Fora da terra, o movimento celeste se da de uma única forma: circular e uniforme. Aristóteles não estava preocupado com a causa do movimento dos corpos, mas sim com o objetivo de seus movimentos. E esse objetivo, acreditava ele, é simples: os corpos se movem para ocupar seu lugar natural no universo. Nas palavras de Aristóteles "O movimento é o que um ser faz para chegar à sua atualização, enquanto ainda não a alcançou".

Aristóteles entendia a região terrestre como constituída por quatro esferas concêntricas com o centro representando a terra seguido por água, ar e fogo, como ilustrado na Figura 1. Todo movimento natural na terra se devia à tendência dos objetos de ocuparem seu lugar natural. Por isso uma pedra quando solta no ar cai rapidamente em direção à terra, enquanto uma pena, que não tem tanta terra quanto uma pedra, cai mais devagar. Como vemos, o senso comum está ao lado de Aristóteles.

Esse pensamento também levou Aristóteles à conclusão de que a terra é o centro do universo, já que as coisas caem para e terra e não para outra parte do universo. Além disso, concluiu que a terra está imóvel no universo. Se não fosse assim, ao jogarmos um objeto verticalmente para cima, ele não retornaria em nossas mãos, como não volta em nossas mãos a chave de casa quando atirada verticalmente para cima de uma moto em movimento ${ }^{1}$ Como já foi dito, é um exercício interessante se imaginar na grécia antiga sendo apresentado a essas ideias e tentar refutá-las. Como podemos provar para alguém em nosso dia-a-dia que é a terra que se move e não o sol? E como

${ }^{1} \mathrm{O}$ que se deve, obviamente, à irregularidade do movimento da moto que não pode ser considerado como $\mathrm{MRU}$ e à resistência do ar, que não pode ser desprezada nesse caso.

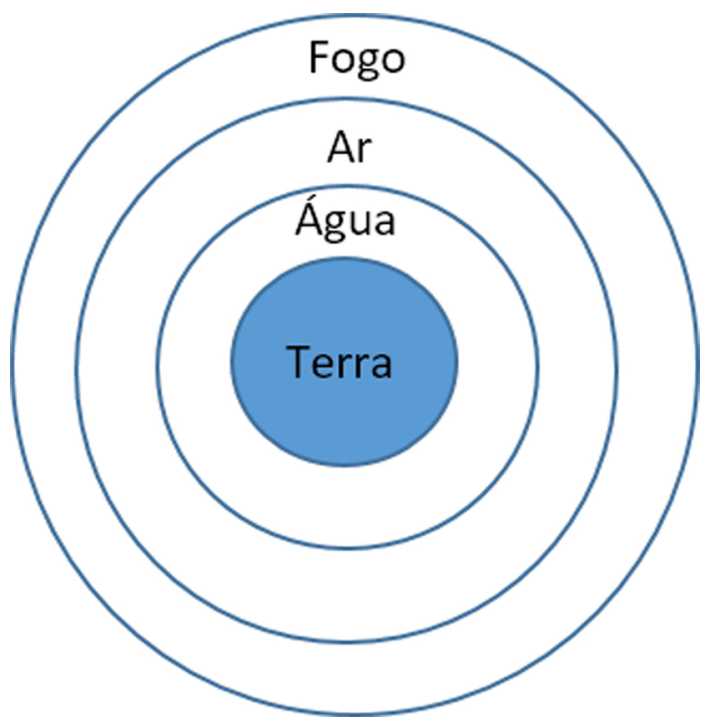

Figura 1: Visão aristotélica da região terrestre.

poderia ser mostrado que todos os corpos possuem o mesmo tempo de queda de uma mesma altura quando em queda livre no vácuo? Pior ainda, como convencer alguém que mesmo cessando as causas do movimento, um corpo ainda permanece em seu estado de movimento retilíneo e uniforme se nenhuma força resultante atuar sobre ele? Essas ideias seriam absurdas para Aristóteles e deveriam ser também para um aluno que ainda não está familiarizado com a mecânica newtoniana.

\section{A Lei da Inércia (primeira lei de Newton)}

Newton enuncia, no Philosophiae Naturalis Principia Mathematica, a lei da inércia da seguinte forma: "Todo corpo continua em seu estado de repouso ou de movimento uniforme em uma linha reta, a menos que seja forçado a mudar aquele estado por forças imprimidas sobre ele". O que quer dizer, continua Newton, que "projéteis continuam em seus movimentos, desde que não sejam retardados pela resistência do ar, ou impelidos para baixo pela força da gravidade" [1]. Disso vemos a justificativa para o uso de cintos de segurança em automóveis e os incotáveis exemplos encontrados nos livros didáticos. Poucos livros didáticos abordam, no entanto, questões de cunho mais fundamental sobre a primeira lei de Newton e isso deixa a compreensão dos alunos sobre essa lei significativamente superficial.

Quando estudamos cinemática, vemos que quando um corpo se move com aceleração nula, seu movimento é retilíneo e uniforme (MRU). Isso induz ao pensamento de que o MRU é consequência da segunda lei de Newton, no caso de não haver força resultante atuando sobre o sistema. Mas se é assim, qual a necessidade da primeira lei de Newton? Essa é uma pergunta que poucos alunos de curso superior são capazes de responder no primeiro 
curso de física básica, quando as leis de Newton são introduzidas ${ }^{2}$ Para eles, parece natural que na ausência de aceleração, um corpo se mova em MRU.

É imprescindível que o aluno entenda que a segunda lei de Newton nos diz como se dá a dinâmica do sistema quando sujeito a força resultante, mas não nos diz nada sobre como se dá essa dinâmica quando o sistema esá livre de força resultante. Sem a primeira lei de Newton não sabemos como é o movimento de um corpo com aceleração nula. É a primeira lei de Newton que imporá que nesse caso o movimento será retilíneo e uniforme. Se perguntássemos para Aristóteles como se dá o movimento de um corpo livre de força resultante, provavelmente ele nos responderia que esse movimento seria circular e uniforme. Ao impor que o movimento livre de força resultante é MRU, qualquer movimento diferente deste será, necessariamente, acelerado. Define-se, dessa forma, um referencial inercial para se medir força e seu efeito de mudança.

De particular interesse, nesse ponto, é chamar a atenção para o fato de que com a primeira lei de Newton temos o que podemos considerar uma primeira definição formal e prática de massa (inercial). Newton chamou de inércia a capacidade que um corpo tem de resistir à mudança em seu estado de MRU, mas essa resistência é tão maior quanto maior é a quantidade de matéria que o corpo possui. A inércia, portanto, pode ser vista como uma medida da própria massa inercial de um corpo.

Newton considera a inércia como uma propriedade intrínseca aos corpos, mas mesmo Newton teve muitas dúvidas sobre essa conclusão. É interessante levantar para questionamento que não é intuitivo pensar que a propriedade dos corpos de resistir à mudança em seu estado de MRU (chamado de inércia) e sua quantidade de matéria sejam a mesma coisa. Na segunda metade do século XIX, Ernst Mach criticou fortemente essa ideia [4]. Para ele, a inércia é o resultado das interações de todos os outros corpos do universo com o corpo em estudo. Caso essas interações fossem eliminadas, para Mach, o corpo em estudo não mais ofereceria resistência à mudança em seu estado de MRU. Em outras palavras, a inércia deixaria de existir. O problema com a proposta de Mach é que dificilmente conseguiremos testá-la experimentalmente.

\section{Conclusão}

Neste trabalho foi apresentado uma proposta de abordagem da primeira lei de Newton tendo por objetivo uma compreensão mais aprofundada do tema por parte dos alunos. Foi defendido que começar fazendo os alunos enxergarem que tal lei não é óbvia, como muitos pensam, é uma abordagem eficaz e gera um aprendizado significativo. Podemos fazer isso apresentando, antes das leis

\footnotetext{
${ }^{2}$ Em minha experiência ministrando aulas de Física básica na universidade Federal de Viçosa e no Centro de Instrução e Adaptação da aeronáutica nenhum aluno me respondeu satisfatoriamente a essa pergunta.
}

de Newton, o pensamento aristotélico do movimento e convidando-os a refutarem tais ideias, hoje tidas pela ciência como erradas. Posteriormente, apresentamos a primeira lei de Newton e, inicialmente, suas consequências mais diretas e perceptíveis no dia-a-dia. Em seguida, apresentamos suas consequências mais profundas e filosóficas.

\section{Referências}

[1] I. Newton, PRincipia(Editora da USP, São Paulo, 2002).

[2] B. Russel, História do Pensamento Ocidental (Nova fronteira, São Paulo, 2013).

[3] J.C. Souza (org), Pré-Socráticos (Nova Cultura, São Paulo, 2000).

[4] A.S.T. Pires, Evolução das Ideias da Física (Livraria da Física, São Paulo, 2011). 